\title{
OBTENÇÃO DO BIODIESEL ATRAVÉS DA TRANSESTERIFICAÇÃO DO ÓLEO DE Moringa Oleífera
} Lam

D. S. Oliveira ${ }^{1}$, X. D. S. Fonseca ${ }^{1}$, P. N. Farias ${ }^{1}$, V. S. Bezerra ${ }^{1}$, C. H. C. Pinto ${ }^{2}$, L. D. Souza ${ }^{2}$, A. G. D. Santos ${ }^{2}$, L. G. O. Matias ${ }^{2}$.

${ }^{2}$ Profs. do departamento de Química - Universidade do Estado do Rio Grande do Norte - UERN, Mossoró-RN.

${ }^{1}$ Licenciandos em Química - Universidade do Estado do Rio Grande do Norte - UERN, Mossoró-RN. danielequimica@hotmail.com

Artigo submetido em dezembro/2011 e aceito em março/2012

\section{RESUMO}

A Moringa Oleifera Lam é uma oleaginosa que tem um grande potencial para a produção de biocombustível no semi-árido nordestino, uma vez que se adapta a várias condições climáticas. A semente produz entre $35 \%$ a $40 \%$ de óleo. O objetivo desse trabalho foi obter o biodiesel através do processo de transesterificação e caracterizar as propriedades físico-químicas do óleo e biodiesel de acordo com as normas estabelecidas pela ANP. O biodiesel foi produzido pela rota metílica com o catalisador $\mathrm{KOH}$. Os resultados mostraram que a semente de moringa produz óleo em boa quantidade com características físicoquímicas adequadas para ser usado como matéria prima na transesterificação para obtenção de biodiesel. $\mathrm{O}$ teor de óleo médio encontrado para as sementes de moringa foi de $40 \%$, fornecendo rendimento de $83,68 \%$ em biodiesel e conversão dos ácidos graxos em ésteres metílicos de 99,9\%.

PALAVRAS-CHAVE: Biodiesel, Transesterificação, Moringa Oleífera Lam.

\section{GETTING THROUGH THE BIODIESEL OIL TRANSESTERIFICATION Moringa Oleífera Lam}

\section{ABSTRACT}

The Moringa Oleifera Lam is an oil tree which has a great potential for biofuel production in semi-arid, as long as it fits in various weather conditions. The seed produces between $35 \%$ and $40 \%$ oil. The aim of this study was to obtain biodiesel through the transesterification process and characterize the oil's physical-chemical properties and biodiesel in accordance with the standards established by the ANP. The biodiesel was produced by methylic route with the catalyst $\mathrm{KOH}$. The results showed that the moringa seed produces oil in good quantity with adequate physical-chemical characteristics to be used as feedstock for transesterification to obtain biodiesel. The average oil content found for moringa seeds was $40 \%, 83,68 \%$ yield of biodiesel and conversion of fatty acids methyl esters of 99,9 $\%$.

KEY-WORDS: Biodiesel, Transesterification, Moringa Oleifera Lam. 


\section{OBTENÇÃO DO BIODIESEL ATRAVÉS DA TRANSESTERIFICAÇÃO DO ÓLEO DE Moringa Oleifera Lam}

\section{INTRODUÇÃO}

O petróleo é um elemento de influência nas relações geopolíticas contemporâneas, desde quando se tornou a matriz energética básica da sociedade industrial e um elemento fundamental para o funcionamento da economia moderna.

Considerando-se o petróleo um recurso natural não-renovável, o biodiesel apresenta-se como alternativa energética, devido ao fato de ser um combustível renovável e biodegradável, podendo substituir o diesel mineral sem necessidade de nenhuma modificação nos motores dieseis já existentes. (RAMOS , 2003 e BARROS, 2007).

De modo geral, o biodiesel foi definido pela "National Biodiesel Board" dos Estados Unidos como um derivado mono-alquil éster de ácidos graxos de cadeia longa, proveniente de fontes renováveis como óleos vegetais ou gordura animal cuja utilização está associada à substituição de combustíveis fósseis em motores de ignição por compressão. O biodiesel é um biocombustível oriundo da biomassa ambientalmente correto, sucedâneo ao óleo diesel mineral, constituído de uma mistura de ésteres metílicos ou etílicos de ácidos graxos, obtidos da reação de transesterificação, esterificação e hidroesterificação de qualquer triglicerídeo derivado de gordura animal ou vegetal com um álcool de cadeia curta. (MEHER, 2006; KNOTHE et al, 2006; QUESSADA., T. P, 2007).

A reação de transesterificação é a etapa da conversão, propriamente dita do óleo ou gordura, em ésteres metílicos ou etílicos de ácidos graxos, que constitui o biodiesel. Pode-se dizer que o processo de transformação de óleos vegetais ou de gordura animal em biodiesel, por transesterificação, é relativamente simples, mas requer rigor com as características das matérias primas, sobretudo se o objetivo for comercializar um biodiesel que efetivamente atenda às exigências legais do país e do mercado internacional (BELTRÃO, 2008; KRAUSE, 2008).

No Brasil, cerca de $75 \%$ do biodiesel produzido é oriundo do óleo extraído da semente de soja (AGROFEL, 2011), mas as alternativas para produção de óleo são diversas e dependem da espécie cultivada em cada região. No Nordeste, algumas culturas se destacam por serem adaptáveis ao clima semi-árido como é o caso da mamona e do pinhão manso. (SLUSZZ, 2006). Neste contexto, uma planta que tem um grande potencial para a produção de biocombustível no semi-árido nordestino é a moringa oleifera (Lam), pois é uma planta que se enquadra em todas as características citadas. Ela é uma planta pertencente à família (Moringaceae), que é composta por apenas um gênero (Moringa) e quatorze espécies conhecidas, nativa do Nordeste da Índia, é cultivada por vários povos do Oriente por seu alto valor alimentar, medicinal, industrial e aplicabilidade no tratamento de águas para o consumo humano (RANGEL, 2010). A árvore é considerada uma das mais úteis para o ser humano, visto que praticamente todas as suas partes podem ser utilizadas para algum fim.

A moringa oleifera (Lam) é uma árvore especial, não apresenta dificuldades quaisquer que sejam os métodos escolhidos para a sua propagação, pode ser pelo plantio direto, produção de mudas a partir de sementes ou de estacas, podendo ser plantada em elevadas altitudes até 2000 metros de altura. Adaptam-se bem as condições climáticas tanto do clima semi-árido como sub-úmido, não sendo necessários altos volumes pluviométricos por ano, é tolerante à seca e produz boa quantidade de óleo. (ESPLAR 2006). A planta não 
apresenta exigências especificas em termos de tipos de solos a não ser a impossibilidade de se desenvolver em solos encharcados.

A idade da árvore na primeira frutificação é variável, em geral, considera-se que a moringa oleifera (Lam) frutifica no primeiro ano nas condições ideais de manejo. Nas regiões semi-áridas da África, a mesma frutifica a partir do segundo ano de vida. A produção das sementes apresenta grandes variações, esse fato está ligado ao manejo da planta, a disponibilidade de água e ao clima podendo chegar a produzir entre 20 a 24 mil sementes por planta com os devidos cuidados adequados. A semente desta árvore produz um óleo amarelo claro de alta qualidade, similar em qualidade ao azeite de oliva, que pode ser de $35 \%$ a $40 \%$ da massa total da semente( RURAL BIOENERGIA ,2010).

Levando-se em consideração que depois da extração do óleo da semente de moringa oleifera (Lam), a torta restante não é tóxica e não perde suas propriedades de coagulação, podendo ser usada como decantador no tratamento de água para o consumo humano (RANGEL, 2010) e como alimentação de animais graças as suas vitaminas e minerais existentes tanto na torta restante da extração como nas folhas e flores da planta, este recurso natural pose ser importante para a economia regional. Com a plantação em alta escala da moringa, pode-se também reduzir o índice de gás carbônico existente no ar. Pela produção intensiva de flores e sementes, estudos recentes recomendam seu plantio para extração de óleo das sementes para produção de biodiesel (RURAL BIOENERGIA, 2010). Outros autores tem obtido óleos e biodiesel de moringa e estudado sua qualidade. (AGUIAR,_2009; BELTRÃO E OLIVEIRA, 2008; MONTEIRO, 2007)

Agência Nacional de Petróleo, Gás Natural e Combustível (ANP), conforme a resolução no 7/2008, Anexo 1/2008, que trata da qualidade do biodiesel produzido, estabelece padrões de qualidade que devem ser obedecidos; (ANP, 2011). Para verificar estes parâmetros é necessário monitorar varias propriedades e verificar se as mesmas estão obedecendo à legislação. (REI, P. A. G. V, 2007)

Assim o objetivo desse trabalho foi extrair e caracterizar o óleo da moringa e baseado em suas características físico-químicas, sintetizar o seu biodiesel através do processo de transesterificação básica do óleo, bem como caracterizar as propriedades físico-químicas do biodiesel de acordo com as normas estabelecidas e verificar se o mesmo se enquadra dentro dos padrões de qualidade exigidos.

\section{METODOLOGIA}

\subsection{EXTRAÇÃO DO ÓLEO DE MORINGA OLEÍFERA LAM}

Inicialmente as sementes de Moringa Oleífera Lam foram coletadas no Campus Central da Universidade do Estado do Rio Grande do Norte (UERN) - Mossoró/RN. Antes da extração as sementes passaram por um processo de limpeza e tratamento. As sementes ficam encapsuladas numa casca sobre a amêndoa que foi retirada com a ajuda de uma espátula. Em seguida, as sementes foram colocadas na estufa para secagem durante 5 horas a temperatura de $105^{\circ} \mathrm{C}$ (tempo necessário para retirada de toda a umidade das sementes). Após serem secas as sementes foram trituradas e postas em papel de filtro que foram fechados para formarem saches para posterior extração do óleo. 
A extração foi realizada com o método Soxhlet utilizando como solvente o hexano, em um sistema de refluxo, por 6 horas. O óleo foi separado do solvente com um evaporador rotativo a pressão reduzida e purificado por secagem na temperatura de $65^{\circ} \mathrm{C}$ por 24 horas, como pode ser observado na Figura 1 . O rendimento do óleo no processo foi definido como sendo a massa de óleo extraída em função da massa de semente de moringa usada na extração.

$\mathrm{R}(\%)=$ Massa de óleo $\times 100 \div$ massa da semente inicial

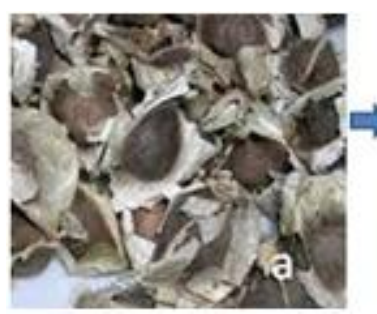

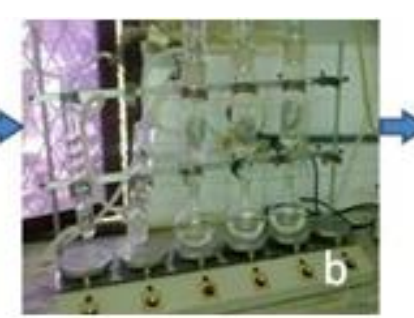

(equação.1)

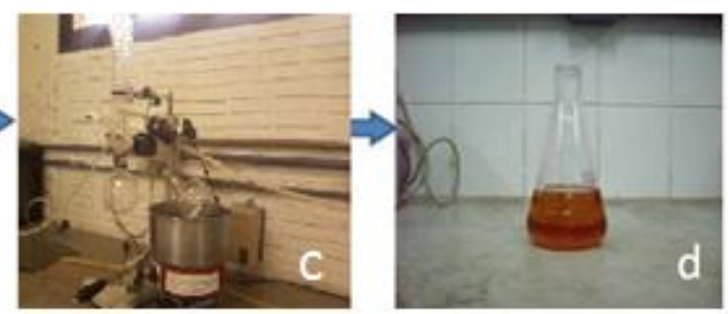

Figura 1: Etapas de obtenção do óleo de moringa oleifera a) Semente de moringa oleifera b) Sistema soxhlet c) Evaporador rotativo d) Óleo de moringa.

\subsection{OBTENÇÃO DO BIODIESEL DE MORINGA OLEÍFERA LAM}

O óleo de Moringa oleifera Lam que foi seco na estufa durante 24 horas para a retirada de água residual foi usado na síntese do biodiesel. A reação foi feita a temperatura ambiente durante 4 horas utilizando uma razão de álcool/óleo de 6:1, sendo $70 \mathrm{~g}$ de álcool para cada $200 \mathrm{~g}$ de óleo, e $1 \%$ do Hidróxido de potássio $(\mathrm{KOH})$, como catalisador básico. Ao término da reação transferiu-se a mistura para um funil de decantação, com o intuito de separar as fases. Após 1 hora em repouso observou-se nitidamente duas fases, a menos densa contendo os ésteres metílicos (biodiesel) e outra mais densa o glicerol (glicerina), as impurezas e os reagentes em excesso. Depois de 24 horas em repouso a segunda fase foi removida do balão restando apenas os ésteres metílicos, como pode ser observado na Figura 2 , este foi lavado com água morna. Para a avaliação do processo de lavagem foi realizado a medida do $\mathrm{pH}$ utilizando fenolftaleína para observar a coloração da água de lavagem que inicialmente tinha coloração rosa e que, posteriormente, com as sucessivas lavagens ficou incolor, sendo finalizada a lavagem neste momento. Em seguida o biodiesel foi seco em uma estufa a $100^{\circ} \mathrm{C}$ para eliminar umidade residual. 

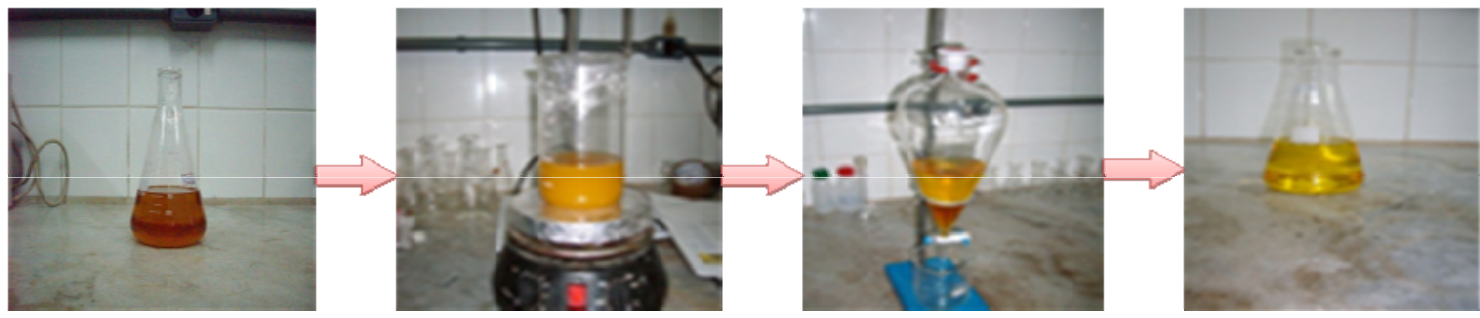

Figura 2: Etapas do processo de obtenção do Biodiesel a) Óleo de Moringa b) Transesterificação c) Separação das fases d) B100

O óleo e o biodiesel de moringa (B100) foram caracterizados segundo o Regulamento Técnico da ANP no 1/2008 contida na resolução no 7/2008 de acordo com as normas da Associação Brasileira de Normas Técnicas (ABNT), das normas internacionais "American Society for Testing and Materials" (ASTM), da "International Organization for Standardization" (ISO) e do "Comité Européen de Normalisation" (CEN). As análises foram realizadas em triplicata no laboratório de físico-química da Universidade do Estado do Rio Grande do Norte (UERN) e o resultado final foi obtido fazendo a média aritmética das análises individuais. As propriedades analisadas foram:

\section{3 Índice de Acidez}

Na determinação do índice de Acidez, pesou-se $2 \mathrm{~g}$ da amostra em um erlenmeyer e adicionou-se $25 \mathrm{~mL}$ de solução de éter com álcool (2:1) previamente neutralizada com uma solução de hidróxido de sódio $0,1 \mathrm{~N}$. em seguida, foram adicionadas 2 gotas do indicador fenolftaleína e titulou-se com solução de $\mathrm{NaOH} 0,1 \mathrm{~N}$ até atingir a coloração rósea.

O calculo de índice de acidez foi realizado segundo a Equação 2.

$$
L A=\frac{(V a-V b) x c x 5,61}{m}
$$

(equação. 2)

Em que la é o índice de acidez, Va é o volume em $(\mathrm{mL})$ da solução de $\mathrm{NaOH} \mathrm{0,1} \mathrm{N}$ gastos na solução; $\mathrm{Vb}$ é o volume em $(\mathrm{mL})$ da solução de $\mathrm{NaOH} 0,1 \mathrm{~N}$ gastos na solução do branco; c é o fator de correção da solução de $\mathrm{NaOH}$ e $\mathrm{m}$ é a massa em (g) da amostra; (SANTOS, 2010).

$\mathrm{O}$ índice de acidez alto tem um efeito bastante negativo no que se diz respeito a qualidade do óleo por que prejudica a reação via catalise básica exigindo maiores quantidades de catalisador, a elevada acidez livre no combustível tem ação negativa sobre os componentes metálicos do motor aumentando a taxa de corrosão dos mesmos.

\subsection{Viscosidade Cinemática}

Para a análise da viscosidade usou-se um viscosímetro segundo a norma ASTM D445, no qual se colocou $70 \mathrm{~mL}$ da amostra no aparelho para aquecer até a temperatura desejada. A temperatura das amostras foi controlada com um termômetro de mercúrio e a temperatura do óleo de aquecimento foi controlada pelo sistema de aquecimento do aparelho. Após o 
equilíbrio ser atingido, fizeram-se as análises medindo-se, em um cronômetro e medindo-se o tempo de escoamento da amostra no furo universal na temperatura de análise.

Com base na Viscosidade Sayboult Universal (SSU), calculou-se a viscosidade cinemática, segundo a equação 3 :

$V C C=\underline{0,224 \times(S S U)-185 ; \text { para } 34 \leq S S U<115}$

(SSU)

(equação.3)

\subsection{Massa específica}

Segundo SANTOS (2010), A densidade é uma propriedade importante e um alto valor pode ser indicativo para restringir a utilização de algum material como matéria-prima para a produção de biodiesel. As medidas foram realizadas em um tensiômetro TD 1 LAUDA devidamente calibrado com água, conforme o manual de operação do aparelho.

\subsection{Tensão Superficial}

A tensão superficial é a força que existe na superfície de líquidos em repouso. As medidas foram realizadas em um tensiômetro TD 1 LAUDA devidamente calibrado conforme o manual de operação do aparelho.

\section{7 Água e Sedimentos}

A determinação do teor de água e sedimento é feita segundo a norma da ASTM D445. Para a medida utilizou-se uma quantidade de $100 \mathrm{~mL}$ da amostra em um tubo de escala legível para até $0,005 \mathrm{~mL}$ centrifugando o tubo numa força centrifuga relativa a 800 RCF durante 10 min em uma centrífuga da marca BE-4004-28. Em seguida observou-se na ponta do tubo o volume de água ou sedimento presente na amostra. O valor máximo permitido pela ANP para a água e sedimento contidos no biodiesel é de $0,050 \%$.

\section{8 Índice de Saponificação}

A determinação do índice de saponificação pesou-se $2 \mathrm{~g}$ da amostra em um erlenmeyer e adicionou-se $20 \mathrm{~mL}$ de solução alcoólica de hidróxido de potássio a $4 \%$. Em seguida, adapta-se o erlenmeyer em um condensador de refluxo e aquece-se até a ebulição branda por $30 \mathrm{~min}$. Posteriormente, adiciona-se 2 gotas do indicador fenolftaleína e em seguida titula-se a quente com solução de ácido clorídrico $0,5 \mathrm{~N}$ até o desaparecimento da coloração rosa.

O calculo para a determinação do índice de saponificação é baseado na equação 4.

$$
I S=\frac{(V A-V B) x C t \times 28}{m}
$$

(equação. 4)

Onde: IS é o índice de saponificação de Koettstorfer, VA é o volume em $\mathrm{mL}$ do $\mathrm{HCL} 0,5$ $\mathrm{N}$, gasto na titulação da amostra; VB é o volume em $\mathrm{mL}$ do $\mathrm{HCL} 0,5 \mathrm{~N}$ gasto na titulação da 
solução do solvente (Branco); Ct é a concentração da solução de $\mathrm{HCl}$; $\mathrm{m}$ é a massa (mg) da amostra.

\subsection{Termogravimetria (TG / DTG)}

Também foi feita Análise Termogravimétrica do óleo e do Biodiesel usando uma termobalança modelo TGA 50 da Shimadzo. As análises foram feitas iniciando-se a $25{ }^{\circ} \mathrm{C}$ e indo até $550^{\circ} \mathrm{C}$, a uma razão de aquecimento $10^{\circ} \mathrm{C} / \mathrm{min}$, sob atmosfera inerte de nitrogênio, com vazão de $25 \mathrm{~mL} / \mathrm{min}$. Foi utilizado cadinho de platina e as massas das amostras foram de aproximadamente $5,0 \mathrm{mg}$.

\section{RESULTADOS E DISCUSSÕES}

\subsection{Teor de óleo e Rendimento da reação de transesterificação}

O teor de óleo médio encontrado para as sementes de moringa foi de $40 \%$, o que excede sensivelmente o teor encontrado na literatura para outras oleaginosas como soja e algodão, como pode ser observado na Tabela 1 que mostra os valores médios encontrados para diversas oleaginosas. Dessa forma, estes valores indicam que esta oleaginosa tem um bom potencial para fornecer óleo para a produção de biodiesel. A baixa viscosidade, o baixo índice de acidez e a ausência de água e impurezas como apresentado na tabela 2 indicaram um óleo de boa qualidade para a síntese básica e deram indícios das condições de reação a serem adotadas como a razão de álcool para óleo de 6/1 e o tempo de reação de 4 hs.

Tabela 1. Teor de óleo de oleaginosas e gordura animal com potencial de uso energético

\begin{tabular}{cc}
\hline \hline Óleos e gorduras & $\begin{array}{c}\text { Conteúdo do } \\
\text { Óleo em (\%) }\end{array}$ \\
\hline \hline Gordura animal & 100 \\
Dendê & 20 \\
Abacate & $7,0-35,0$ \\
Coco & $55,0-60,0$ \\
Babaçu & 66,0 \\
Girassol & $38,0-48,0$ \\
Colza/Canola & $40,0-48,0$ \\
Mamona & $43,0-45,0$ \\
Amendoim & $40,0-43,0$ \\
Soja & 17,0 \\
Algodão & 15,0 \\
\hline \hline
\end{tabular}

Fonte: KRAUSE (2008)

Nessas condições a transesterificação do óleo de moringa em meio básico foi bastante satisfatória dando rendimento de $83,68 \%$ em biodiesel, através do método 
gravimétrico, mesmo com a reação não sendo otimizada. Este rendimento se aproxima de outras oleaginosas como "algodão 92,2 \%, girassol 98,6 \% e ultrapassa o valor encontrado para o dendê de 74,8\%" (SANTOS, 2010).

O rendimento do biodiesel foi calculado como sendo a massa de biodiesel pesada depois da reação em função da massa de óleo empregada na transesterificação, (Rendimento $(\%)=$ Massa biodiesel $* 100 /$ Massa óleo empregada).

A tabela 2 apresenta o teor de óleo, o rendimento e a caracterização físico-química do óleo e do biodiesel de moringa.

Tabela 2. Teor de óleo, rendimento e propriedades físico-químicas do óleo e do biodiesel metílico de moringa oleifera Lam.

\begin{tabular}{lllll}
\hline Caracterizações & Óleo de Moringa & $\begin{array}{l}\text { Biodiesel } \\
\text { Moringa }\end{array}$ & de Limites ANP
\end{tabular}

\begin{tabular}{|c|c|c|c|}
\hline Teor de Óleo (\%) & 40 & - & $\mathrm{NC}^{*}$ \\
\hline Rendimento do Biodiesel (\%) & - & 83,68 & NC* \\
\hline Índice de acidez (mg KOH/g) & 0,047 & 0,028 & 0,5 \\
\hline Índice de saponificação (mg KOH/g) & 182,39 & 190,73 & NC* \\
\hline Densidade (g/dm3) & 886 & 887 & $875-900$ \\
\hline Viscosidade (Cst) & 33,24 & 13,56 & $3,0-6,0$ \\
\hline Tensão superficial (mN/n) & 29,8 & 28,7 & NC* \\
\hline Água e sedimentos (\%) & $\mathbf{0}$ & $\mathbf{0}$ & 0,050 \\
\hline
\end{tabular}

\subsection{VISCOSIDADE}

No óleo a viscosidade é parâmetro de referência que ajuda na determinação do tempo de reação de transesterificação, sendo que uma viscosidade elevada aumenta o tempo da síntese. O baixo valor encontrado em comparação com a de outros óleos estudados pelos mesmos autores indicaram o tempo de reação de $4 \mathrm{~h}$ usado. (SOUZA et al., 2010a, 2010b, 2011a e 2011b)

Como pode ser analisado na Tabela 2, o biodiesel apresentou valores de viscosidade acima da norma estabelecida pela ANP que é de 3,0-6,0 (Cst), tal valor é influenciado pelas propriedades do ácido oléico (C18:1), ácido graxo presente em grande quantidade no óleo de moringa que promove as interações intermoleculares como forças Van der Walls que se acentuam devido a molécula possuir uma grande massa molecular, contribuindo para o aumento do tempo de escoamento do biodiesel. No entanto, foi observada uma redução significativa na viscosidade em relação ao óleo natural, essa diminuição está relacionada à reação de transesterificação do óleo, sendo que o principal objetivo desta reação é diminuir este parâmetro. Neste sentido foi observada uma redução significativa na viscosidade em relação ao óleo in natura. Além disso, a molécula apresenta uma insaturação com 
conformação cis característica de ácidos graxos (ALLINGER et al., 1978) o que pode ajudar a diminuir a viscosidade devido o enfraquecimento das forças de dispersão e ao empacotamento das moléculas que é melhorado pela rigidez que essa conformação impõe a molécula. Devido a isso os valores encontrados para a viscosidade do biodiesel são baixos em relação ao óleo. Mesmo assim, o valor alto impõe cuidados e restrições ao uso direto do biodiesel de moringa, podendo ser usado em misturas nos motores ciclo-diesel.

\subsection{MASSA ESPECÍFICA}

Da mesma forma que a viscosidade e pelos mesmos motivos estruturais, a densidade também é influenciada pelas propriedades do ácido oléico. A configuração do ácido oléico diminui tanto a área de contato entre as moléculas como as forças atração secundárias (ligações hidrogênio e dispersão), o que dificulta a agregação entre as mesmas e impede o empacotamento pelo aumento do espaço entre as moléculas, resultando em aumento da densidade. Isto, no entanto, é compensado pelo aumento da rigidez da cadeia que facilita o empacotamento e o resultado final é refletido na densidade. No biodiesel o decréscimo das ligações de hidrogênio causado pela esterificação resulta em um ligeiro aumento de densidade. Com respeito à legislação, os resultados mostraram que tanto o óleo de moringa, como o biodiesel, apresentaram densidade dento das normas estabelecidas. Ele pode ser usado como combustível, apesar que a alta densidade pode causar problemas relacionados com a injeção do combustível no motor prejudicando seu desempenho (SANTOS, 2010).

\subsection{TENSÃO SUPERFICIAL}

Considerou-se que apesar de não existir um padrão normalizado para a tensão superficial, o seu valor foi considerado alto para óleo e o biodiesel de moringa, sendo o valor mais elevado no óleo, devido à presença de ligações de hidrogênio que este possui. Assim as interações intermoleculares se tornam mais fortes, significando que será necessária uma maior temperatura para romper as forças e assim permitir que as moléculas deixem o estado líquido e passem para o vapor. $O$ valor alto de tensão superficial implica em dificuldades de volatilizar o combustível que resultam em aumento da temperatura de funcionamento do motor e podem resultar em diminuição da vida útil do mesmo. Valores altos se caracterizam, portanto, em resultado insatisfatório, tendo em vista que, uma menor tensão superficial facilita a volatilização do combustível proporcionando uma queima mais completa, diminuindo a possibilidade de formação de resíduos sólidos (fuligens) que podem prejudicar o funcionamento do motor e são ambientalmente ruins.

\subsection{TEOR DE ÁGUA E SEDIMENTOS}

Os resultados, tanto para o óleo, como para o biodiesel não apresentaram água e sedimentos, o que é muito bom. Com relação ao óleo, traços de água residual podem promover reações indesejadas, como hidrólise promovida pela água, o que pode resultar em ácidos graxos livres aumentando a acidez do sistema e saponificação dos ácidos graxos, prejudicando o rendimento da reação. Dessa forma, o óleo por apresentar ótimo resultado pode ser usado sem problemas na obtenção de biodiesel. Já sua presença no biodiesel aumenta a acidez do combustível e pode assim, aumentar a sua corrosividade. 


\section{6. ÍNDICE DE ACIDEZ}

Os valores obtidos no índice de acidez para o biodiesel de moringa estão dentro da especificação que é de $0,5 \mathrm{mg}$ de $\mathrm{KOH} / \mathrm{g}$. Comparando com o óleo, observou-se que o valor apresentado é bem menor. Dessa forma, observa-se que tanto o óleo como o biodiesel são pouco corrosivos aos componentes metálicos presentes no motor. Um baixo índice de acidez para o óleo minimiza as reações indesejadas como a saponificação dos ácidos graxos livres promovida pelo meio básico do catalisador durante a reação.

\section{7. ÍNDICE DE SAPONIFICAÇÃO}

O índice de saponificação do óleo de moringa foi de 182,39 mg KOH/g e é menor em comparação com o do biodiesel que foi de $190,73 \mathrm{mg} \mathrm{KOH} / \mathrm{g}$. Os resultados são semelhantes aos encontrados para outras oleaginosas de composição semelhante (PEREIRA E COLABORADORES, 2010).

\subsection{TERMOGRAVIMETRIA (TG/DTG)}

As curvas TG/DTG do óleo e do biodiesel podem ser visualizadas nas figuras 3 e 4, respectivamente. Pode-se observar que o óleo de Moringa Oleífera Lam apresentou três eventos térmicos, o primeiro a uma temperatura máxima de $91,4^{\circ} \mathrm{C}$ ocorre devido o óleo conter pequena quantidade de água residual, o segundo ocorre a uma temperatura de $410,7^{\circ} \mathrm{C}$, sendo o maior evento, e, provavelmente, se deve à decomposição do ácido graxo majoritário e o terceiro na temperatura de $450^{\circ} \mathrm{C}$, pode ser atribuído a ácidos graxos minoritários de maior massa molar e ou impurezas existentes no óleo. Com relação a curva termogravimétrica do biodiesel, observou-se que houve uma única perda quando atingiu à temperatura de $229,4^{\circ} \mathrm{C}$, que pode ser atribuída à volatilização e/ou decomposição dos ésteres metílicos constituintes do material. O resultado mostra que de acordo com Santos (2010a) a conversão foi de 99,9\% de triglicerídeos em ésteres metílicos. Este valor é bem maior que o rendimento obtido na reação o que é um indício de que o pico de maior temperatura no termograma do óleo deve ser devido a impurezas que não reagiram.

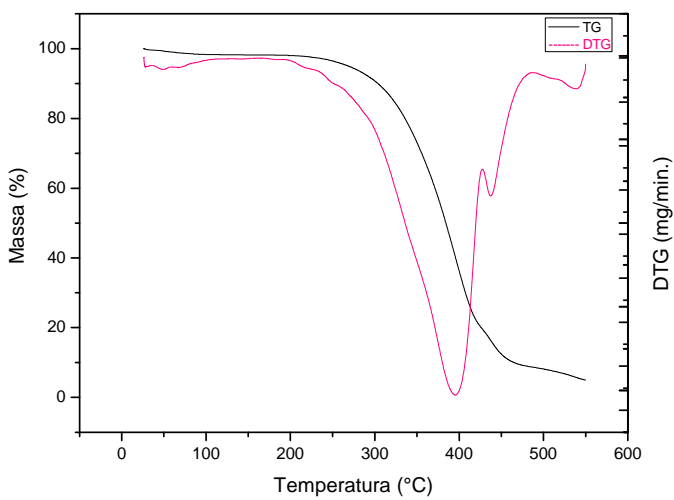

Figura 3- Termogramas do óleo

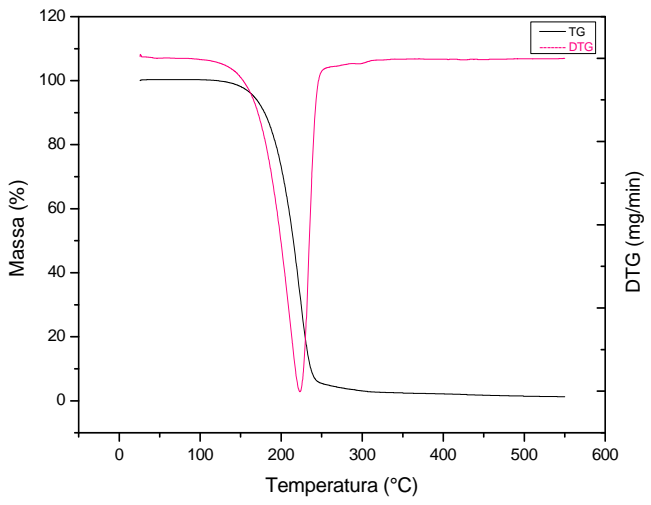

Figura 4- Termogramas do biodiesel 


\section{CONCLUSÕES}

$\checkmark$ Os resultados mostraram que a semente de Moringa Oleífera Lam produz óleo em boa quantidade $(40 \%)$ e com boas características físico-químicas para ser usado como matéria prima na transesterificação básica para obtenção de biodiesel.

$\checkmark$ A transesterificação do óleo de Moringa Oleífera Lam em biodiesel (B100) metílico foi bastante satisfatória tendo rendimento de $83,68 \%$ e $99,9 \%$ de conversão como constatado pela análise termogravimétrica.

$\checkmark$ As características físico-químicas massa específica, água, sedimentos e índice de acidez para o biodiesel de moringa apresentaram-se de acordo com as normas da Resolução no 07/2008 da Agência Nacional de Petróleo, Gás Natural e Biocombustíveis (ANP).

$\checkmark$ A viscosidade do biodiesel está acima do permitido pela legislação.

\section{REFERÊNCIAS BIBLIOGRÁFICAS}

1. Agência Nacional de Petróleo, Gás Natural e Biocombustíveis. Disponível em:< www.anp.gov.br>. Acesso em: 25 dez. 2010.

2. Agência Nacional de Petróleo, Gás Natural e Biocombustíveis. RESOLUÇÂO no 7, de 19/03/2008-DOU-20/03/2008.

Disponível

em:

http://www.anp.gov.br/biocombustiveis/biodiesel.asp>. Acesso em: 21 nov. 2011.

3. AGUIAR, R. T.; Estudo Físico-químico e Térmico do Biodiesel Etílico Feito com Óleo de Moringa Oleifera. ENCONTRO NACIONAL DE MORINGA, Aracajú. SE. 2009.

4. ALLINGER, N. L.; CAVA, M. P.; JONGH, D. C,; JOHNSON, C. R.; LEBEL, N. A.; STEVENS, C. L.; Química Orgânica, Ed. Guanabara: Rio de Janeiro,v16 p 964,1978.

5. BARROS, E. V; Matriz Energética Mundial e a Competitividade das Nações: Bases de uma Nova Geopolítica. ENGEVISTA, v9, n.1, p. 47-56,2007.

6. BRASIL. Anuário Estatístico Brasileiro do Petróleo, Gás Natural e Biocombustíveis / Agência Nacional do Petróleo, Gás Natural e Biocombustíveis. Rio de Janeiro: ANP, 2008.

7. BELTRÃO, N. E. M. E OliVEIRA, M. I. P. - EMBRAPA ALGODÃO. Oleaginosas e seus óleos: Vantagens e Desvantagens para Produção de Biodiesel. Campina Grande, 2008.

8. European Biodiesel Board-EBB. Disponível em: $<$ http://translate.google.com.br/translate?hl=pt-BR\&sl=en\&u=http://www.ebbeu.org/\&ei=c4m0TOvyAYOC8gb_rJyPDA\&sa=X\&oi=translate\&ct=result\&resnum $=2 \& v e d=0 C C$ MQ7gEwAQ\&prev=/search\%3Fq\%3Dhttp://www.ebbeu.org/media.php\%26hl\%3DptBR\%26biw\%3D1024\%26bih\%3D577>. Acesso em: 12 out. 2010. 
9. Agrofel, soja ainda é a principal matéria-prima. Disponível em: < http://www.agrofel.com.br/noticia.php?id=246>. Acesso em: 22 nov. 2011.

10. ESPLAR; Moringa. Disponível em: <http://www.esplar.org.br/publicacoes/moringa.htm>. Acesso em: 23 nov. 2011.

11. KNOTHE, G.; GERPEN, J. V.; KRAHL, J.; RAMOS, L. P. Manual de Biodiesel. São Paulo: Edgard Blücher,v 16 , p $340,2006$.

12. KRAUSE, L. C. Desenvolvimento do Processo de Produção de Biodiesel de Origem Animal. 2008. f. 147 tese (Doutorado em Química) - Universidade Federal de Porto Alegre, Porto Alegre, RS, 2008.

13. MEHER, L. C.; SAGAR, D. V.; NAIK, S. N.; Renew. Sustain. Energy Ver,v 10, p 248,2004.

14. MONTEIRO, J. M. G.; Plantio de Oleaginosas por Agricultores Familiares do Semi-árido Nordestino para Produção de Biodiesel como uma Estratégia de Mitigação e Adaptação às Mudanças Climáticas. Tese de Doutorado. Rio de Janeiro- RJ - 2007.

15. NATIONAL BIODIESEL BOARD. In: Congresso Internacional de Biocombustíveis líquidos, 1998, Curitiba. Anais... Curitiba: Instituto de Tecnologia do Paraná; Secretaria de Estado da Ciência, Tecnologia e Ensino Superior, 1998.

16. QUESSADA., T. P.; Obtenção de Biodiesel a partir de óleo de Soja e Milho Utilizando Catalisadores Básicos e Ácido. Londrina-PR. 2007.

17. RANGEL, M. S. Moringa Oleifera: um purificador natural de água e complemento alimentar para o nordeste do Brasil. Disponível em: <http://www.jardimdeflores.com.br/floresefolhas/A10moringa.htm>. Acesso 10 maio. 2011.

18. REI, P. A. G. V.; Procedimentos laboratoriais para o controlo da qualidade do Biodiesel. Universidade Técnica Lisboa. Lisboa-Portugal 2007.

RURAL BIOENERGIA. Disponível em: http://www.ruralbioenergia.com.br/default.asp?tipo=1\&secao=moringa.asp > Acesso em: 02 Nov. 2011.

19. RURAL BIOENERGIA. Disponível em: http://www.ruralbioenergia.com.br/default.asp?tipo=1\&secao=moringa.asp >. Acesso 02 dez. 2010.

20. SANTOS, A. G. D. Avaliação da estabilidade térmica do biodiesel de algodão, girassol, dendê e sebo bovino. Dissertação (Mestrado em Química), UFRN, Natal, RN 2010.

21. ARAUJO, A. M. M ; COSTA, E. J. P ; MATIAS, L. G. O ; SOUZA, L.D; SOUZA, F. S. Jr . AVALIAÇÃO DAS PROPRIEDADES FÍSICO-QUÍMICAS DO ÓLEO E DO BIODIESEL DE PINHÃO MANSO CATALISADO POR IODO SUBLIMADO. Química no Brasil, v. 4, p. 21-26, 2011. 
22. SANTOS, A. G. D. ; CALDEIRA, V. P. S. ; FARIAS, M. F. ; ARAÚJO, A. S. ; SOUZA, L.D.; BARROS, Allan K. Characterization and kinetic study of sunflower oil and biodiesel. Journal of Thermal Analysis and Calorimetry, v. 106, p. 747-751, 2011.

23. SOUZA, L.D.; ADILSON, B ; ARAUJO, A. M. M ; EVANGELISTA, COSTA,J. P. ; MATIAS, L. G. O. Produção e caracterização físico-química de biodieseis via catalise heterogênea utilizando Iodo sublimado. Química no Brasil, v. 4, p. 234, 2010.

24. ARAUJO, A. S. ; SOUZA, L.D. ; SANTOS, A. G. D ; CALDEIRA V.P.S. Model-free kinetics applied to volatilization of Brazilian sunflower oil, and its respective biodiesel, Thermochimica Acta (Print), v. 1, p. 1-14, 2010.

25. SLUSZZ, T. M; J. A. D. Características das potenciais culturas matérias-primas do biodiesel e sua adoção pela agricultura familiar. XLIV CONGRESSO DA SOBER. Fortaleza-CE. 2006. 